\title{
A FAST ENGINEERING TOOL FOR SIMULATION AND DESIGN OF PROPELLANT MANAGEMENT SYSTEMS IN LIQUID PROPELLED LAUNCHER STAGES
}

\author{
A. van Foreest ${ }^{1}$, M. Sippel ${ }^{1}$, and A. Isselhorst ${ }^{2}$ \\ ${ }^{1}$ Space Launcher Systems Analysis (SART), DLR \\ Bremen 28359, Germany \\ ${ }^{2}$ EADS Astrium ST, Astrium GmbH \\ Airbus-Allee 1, Bremen 28199, Germany
}

\begin{abstract}
At the Space Launcher System Analysis (SART) department of DLR, an engineering tool for simulating propellant management systems is under development. The tool is called PMP (Propellant Management Program). This paper describes the tool and some of the models the tool uses. Some models have been adapted or added and some will be implemented in the future. The paper also describes the results of a test case in comparison with the EADS Astrium EUCES tool.
\end{abstract}

\section{INTRODUCTION}

A well designed propellant management system in rocket stages is of crucial importance for successful launcher design. The propellant management system can be optimized such that propellant residuals and loaded propellant are minimized. This is especially important for upper stages where each kilogram saved can be directly added to the payload. To obtain an efficient design, fast engineering methods (CPU time on the order of seconds, maximum a few minutes) are required to simulate propellant behavior and propellant management systems. This way propellant management can be integrated in the preliminary design phase where different propellant management systems can be compared and a trade-off can be made. Within the German national program "cooperation project upper stage," the SART department of DLR in Bremen is developing a tool for this purpose. The tool is called PMP (Propellant Management Program).

The main task of the propellant management system is to make sure that propellant enters the engine under the right conditions. Typically, about $90 \%$ of the launcher takeoff mass consists of propellant. The most obvious way to

This is an Open Access article distributed under the terms of the Creative Commons Attribution-Noncommercial License 3.0, which permits unrestricted use, distribution, and reproduction in any noncommercial medium, provided the original work is properly cited. 
minimize propellant mass is probably to increase the specific impulse of the engine. But engine performance cannot be increased infinitely. In fact, current rocket engine technology reaches its limits. It is, therefore, important to optimize the propellant management system to minimize propellant losses (for example, residual propellant and propellant boiloff).

In its current form, the PMP tool calculates amongst others the required pressurization gas mass, pressure losses throughout the propellant feed system, pressure at all locations, and includes a simple method for determining evaporated propellant mass and selfpressurization. Visualization of the propellant management system is also possible (Fig. 1). For the future, some extensions and improvements are foreseen. For example, a more detailed model for liquid evaporation and liquid-gas stratification is to be implemented. Also, a model for propellant slosh is foreseen.

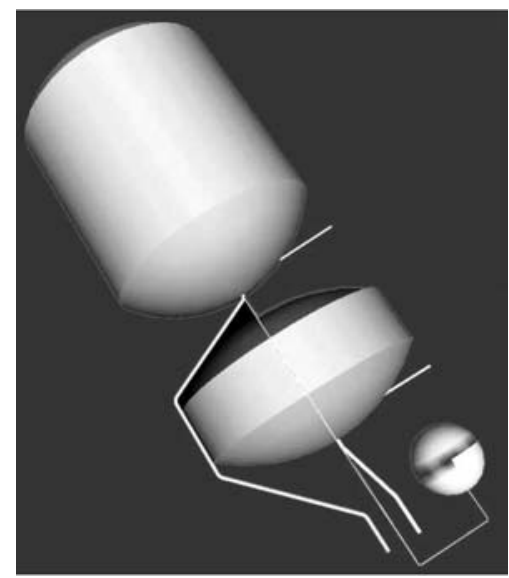

Figure 1 Visualization of upper stage propellant management system as automatically generated by PMP Propellant slosh can create undesired forces which have to be counteracted by the attitude control system. It can also lead to undesired thermodynamic effects like strong pressure drops. Below, the example of an upper stage propellant management simulation is presented and compared to EUCES, a tool based on EcosimPro and used at Astrium.

\section{LOGIC OF THE PROGRAM}

The goal of PMP is to quickly simulate a propellant management system. The tool is not intended for detailed simulation of each physical phenomenon, but rather it should be capable of providing an estimation of integral values.

The input data of PMP consists of two parts: a mission specific part and a propellant system specific part. For the mission specific part, the user has to specify the mission duration and the desired tank pressure. In addition, the user may specify liquid outflow (propellant mass flow), acceleration, external temperatures, and radiative heat flux. The mission specific input can be defined as a function of time. The propellant system specific input consists, for example, of wall thickness, materials, propellant mass, initial propellant temperature, and tank geometry. This input is not a function of time. After providing the input, the PMP is capable of calculating the following data: pressure (includ- 
ing hydrostatic pressure); pipeline pressure drops; required pressurization mass; masses of all components; temperatures of the ullage and liquid; propellant loss (evaporation, venting); and Net Positive Suction Pressure (NPSP).

During the simulation, the pressure in the tanks will start to vary because of tank drainage and propellant boiloff. Propellant Management Program adapts the pressurization gas mass flow such that the desired pressure in the tank is reached. If the pressure in the tank exceeds a maximum, gas is vented until the desired pressure is reached.

Using tank pressure, hydrostatic pressure, pipeline radius, material properties and pipeline geometry (length and bends), the velocity and pressure at each location in the pipeline can be calculated. Using the pressure at the feedline exit (engine inlet), the NPSP is calculated. The NPSP is a very important parameter in Propellant Management System design. If it is too low, cavitation may take place in the turbopump which can lead to catastrophic failures.

\section{PHASE CHANGE MODELS}

A major improvement in PMP has been made for the fluid temperature and phase change models. The old model assumed the liquid temperature to be homogenous and constant. It was also assumed that the heat flux to the liquid was consumed to evaporate a certain amount of liquid. The amount of liquid evaporated was calculated by dividing the heat flux into the liquid by the energy required to heat up the liquid to the boiling temperature plus the heat of evaporation plus the energy required to heat up the evaporated liquid to the ullage gas temperature. The liquid temperature was assumed to remain unchanged:

$$
\dot{m}_{\mathrm{vap}}=\frac{\dot{Q}_{\mathrm{liq}}}{c_{p_{\text {liq }}}\left(T_{\mathrm{sat}}-T_{\text {liq }}\right)+h_{\mathrm{vap}}+c_{p_{\text {gas }}}\left(T_{\text {gas }}-T_{\text {sat }}\right)}
$$

where $\dot{m}_{\text {vap }}$ is the evaporated liquid mass, $\mathrm{kg} / \mathrm{s} ; \dot{Q}_{\text {liq }}$ is the heat flux to the liquid, $\mathrm{J} / \mathrm{s} ; c_{p_{\text {liq }}}$ is the specific heat at constant pressure for the liquid, $\mathrm{J} / \mathrm{kg} / \mathrm{K}$; $c_{p_{\text {gas }}}$ is the specific heat at constant pressure for the gas, $\mathrm{J} / \mathrm{kg} / \mathrm{K} ; T_{\text {sat }}$ is the saturation temperature, $\mathrm{K} ; T_{\text {liq }}$ is the liquid temperature, $\mathrm{K} ; T_{\text {gas }}$ is the gas temperature, $\mathrm{K}$; and $h_{\mathrm{vap}}$ is the heat of vaporization, $\mathrm{J} / \mathrm{kg}$.

Apart from the fact that liquid temperature was assumed constant, the model has some additional shortcomings and therefore was adapted. In reality, some liquid can evaporate even without energy inputs from the surroundings. According to the evaporation model based on kinetic theory $[1,2]$, the evaporated mass is a function of the saturation pressure of the liquid and the partial vapor pressure in the ullage: 


$$
\dot{m}_{\mathrm{vap}}=\sigma A \sqrt{\frac{M}{2 \pi R T}}\left(P_{l}^{\mathrm{sat}}-P_{v}\right)
$$

where $\dot{m}_{\text {vap }}$ is the evaporated liquid mass, $\mathrm{kg} / \mathrm{s} ; \sigma$ is the accommodation coefficient; $A$ is the liquid-gas interface surface area, $\mathrm{m}^{2} ; M$ is the molecular mass, $\mathrm{kg} / \mathrm{mol} ; R$ is the universal gas constant, $8314.4 \mathrm{~J} / \mathrm{kg} / \mathrm{mol} / \mathrm{K} ; T$ is the temperature at the liquid-vapor interface, $\mathrm{K} ; P_{l}^{\text {sat }}$ is the liquid saturation pressure, $\mathrm{Pa}$; and $P_{v}$ is the vapor pressure (or partial pressure of the liquid vapor in case of gas mixture), Pa.

As long as there is a positive pressure difference, liquid will evaporate even if there is no energy input from the surroundings. In this case, energy will be extracted from the liquid and the liquid temperature will drop. If the liquid saturation pressure drops below the partial vapor in the gas (the pressure difference is negative), the vapor will start to condensate.

The liquid temperature can be calculated by determining the net heat input into the liquid. To obtain the net heat input, the heat required for evaporation of the liquid mass determined by Eq. (1) is subtracted from the heat input into the liquid from the surroundings.

The problem when using this model is the determination of the accommodation coefficient. This coefficient is a measure for the chance for a molecule to undergo phase change. The accommodation coefficient can vary from the values 0 (no phase change) to 1 (maximum evaporation rate). Values for this accommodation coefficient are hard to obtain and the values indicated in the literature tend to vary over a large range.

The kinetic theory may not be valid for all fluids. In such cases, the accommodation coefficient can be a "tuning" parameter to adapt the numerical results to the measured data, rather than a real "physical" parameter. For these cases, limiting the accommodation coefficient between 0 and 1 makes no physical sense anymore.

\section{EXAMPLE}

Propellant Management Program including the new phase change model was compared to the EADS Astrium EUCES tool. Like PMP, EUCES is a propellant management tool which calculates propellant conditions in tanks and pipelines [3, 4]. However, the goals of each tool are somewhat different. Whereas the PMP is meant to quickly determine the integral values of the propellant management system, EUCES simulates the processes on a more detailed level.

EUCES has been extensively tested. It is therefore interesting to compare PMP with EUCES. A simple, adiabatic tank model without any heat transfer between propellant and tank wall but including propellant outflow has been set up. The tank is pressurized using helium as a pressurant. Using this 
Table 1 The LOx tank data

\begin{tabular}{lc}
\hline LOx mass, $\mathrm{kg}$ & 28330 \\
LOx mass flow, $\mathrm{kg} / \mathrm{s}$ & 34.2 \\
Burn time, $\mathrm{s}$ & 802 \\
LOx tank pressure, bar & 3 \\
LOx initial temperature, $\mathrm{K}$ & 90.5 \\
Helium pressurant initial temperature, $\mathrm{K}$ & 270 \\
Helium pressurant initial storage pressure, bar & 393 \\
Heat transfer coefficient between ullage and liquid, $\mathrm{W} /\left(\mathrm{m}^{2} \mathrm{~K}\right)$ & 5 \\
\hline
\end{tabular}

simplified model, some basic things such as evaporated propellant mass, pressurisation gas mass, ullage temperature, and heat transfer between liquid and ullage could be compared.

The test case concerns a model of the upper-stage LOx tank of the WOTAN K3 launcher design. The WOTAN launcher has been jointly designed by EADS Astrium and DLR-SART [5]. The input data for the test case are presented in Table 1. In Fig. 2, it can be seen that the upper stage tanks as modeled in the PMP are not an exact representation of the actual design. For example, the cylindrical sections in the middle of the tanks are a bit higher in the PMP representation.
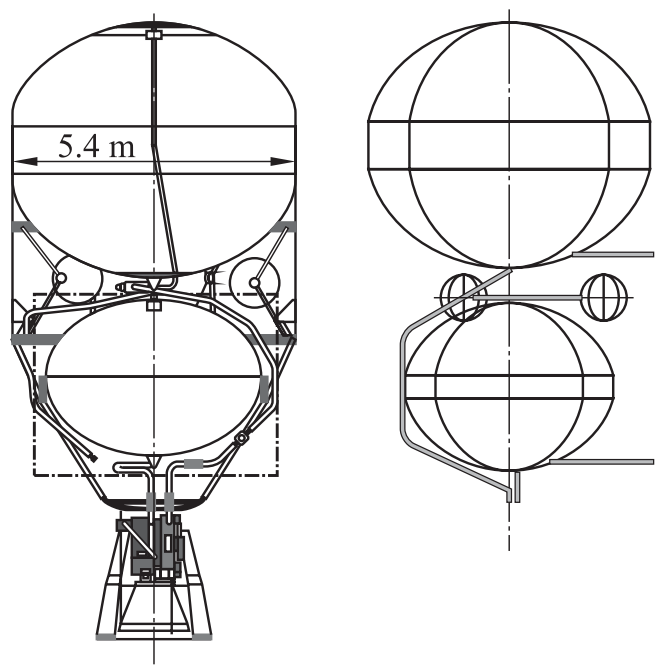

Figure 2 The WOTAN K3 upper stage, with the LOx tank marked by a dot-dashed square. The PMP model with the approximated geometry is shown on the right This is explained by the fact that the PMP can only model cylinders and spherical segments, but the actual tank domes are not the spherical segments. However, this is usually a very good approximation of the tank shape.

Figure $3 a$ shows the heat transfer between liquid and ullage. The negative numbers mean heat is transferred from the ullage to the liquid. The heat transfer coefficient between liquid and ullage has been set to equal values for both cases (see Table 1). However, a difference in heat transfer can still be seen. This can be explained by the fact that when using the PMP, the tank geometry is approximated. Heat transfer between the liquid and ullage is a function of the 


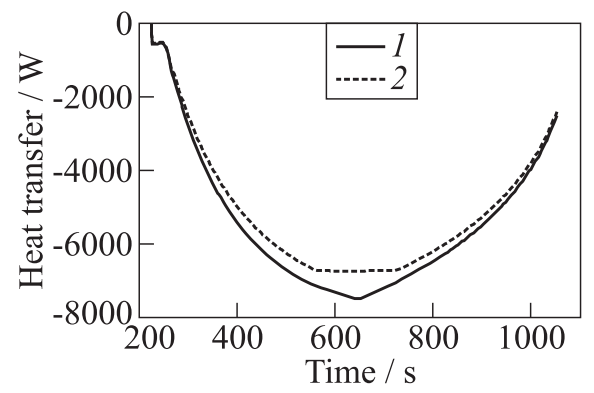

(a)

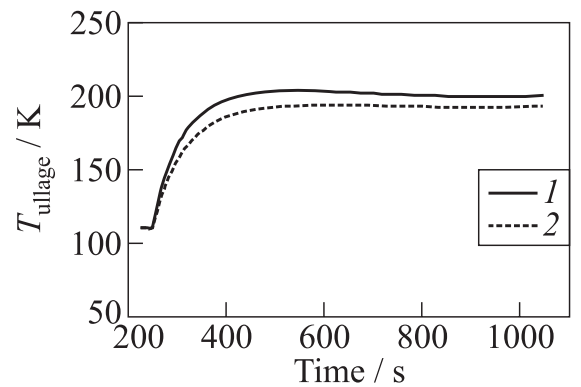

(c)

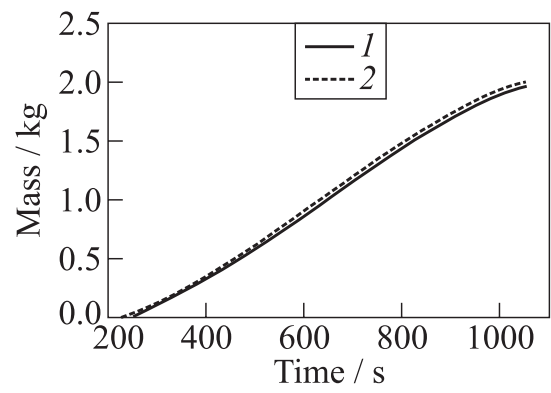

(b)

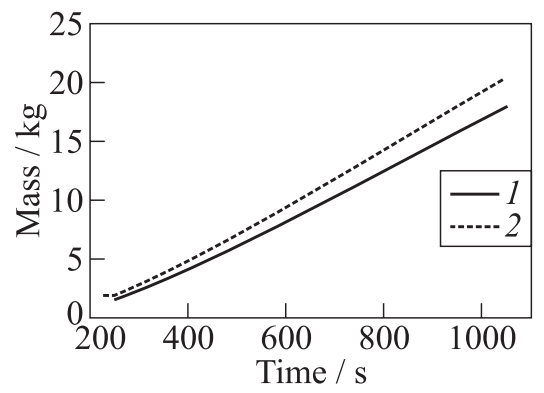

(d)

Figure 3 Heat transfer between liquid and ullage $(a)$; evaporated liquid mass $(b)$; ullage temperature evolution $(c)$; and pressurization gas mass $(d): 1$ - EUCES; and 2 - PMP

heat transfer coefficient, liquid surface area, and temperature difference between liquid and ullage. As the tank is drained, the liquid surface area changes. Because tank geometries for both cases differ slightly, the liquid surface area is also different and, therefore, there is a difference in heat transfer.

The simulation begins at about $t=220 \mathrm{~s}$, after first stage separation. At this time, the tank is almost completely filled. The liquid surface area is small and the heat transfer is low. At about $t=620 \mathrm{~s}$, the tank is filled to a half. Here, the tank radius is the largest and the liquid surface area reaches the maximum value. Therefore, the heat transfer has also reached its maximum value.

Figure $3 b$ shows the evaporated propellant mass. The evaporation model in PMP requires the input of the accommodation coefficient. The data on accommodation coefficients for oxygen are hard to obtain. The coefficient has been chosen such that the evaporated mass equals the evaporated mass in the EUCES. This results in a very small accommodation coefficient of $10^{-6}$.

The development of the ullage temperature is shown in Fig. $3 c$. The PMP simulation results in a somewhat lower ullage temperature, which seems a bit strange because according to Fig. $3 a$, the heat transferred from the ullage into the 
liquid is less in the PMP case. Therefore, one could expect the ullage temperature to be higher.

The pressurization gas mass (Helium) is higher for the PMP case, as can be seen in Fig. 3d. A lower ullage temperature will lead to a lower pressure and, therefore, the pressurization gas mass must be higher to maintain the desired tank pressure.

\section{THERMAL STRATIFICATION IN THE LIQUID}

Thermal stratification in the liquid is important because a change in the liquid temperature also means a change in the NPSP. If the liquid temperature is too high, NPSP can drop below critical values and cavitation can take place in the turbopumps.

Stratification of the liquid can also have a negative side effect when propellant sloshing occurs. Propellant sloshing is not yet implemented in the PMP. Propellant sloshing dynamics leads to undesired mechanical loads and can also lead to undesired thermodynamic effects such as strong pressure drops due to the mixing of thermal layers in the liquid. The dynamics of sloshing and its mechanical loads are well understood and analytical relations exist. Implementing these into the program should be fairly straightforward. The thermodynamic aspect of sloshing is a more complex subject. Currently, experiments are carried out by the Centre of Applied Spaceflight and Microgravity (ZARM) in Bremen to investigate the latter. Simplified models are extracted from these experiments and from numerical analysis with three-dimensional (3D) flow solvers such as the commercially available FLOW $3 \mathrm{D}$ code [2]. It is foreseen to implement these in PMP.

Thermal stratification in the liquid can be modeled by assuming that the tank is cylindrical and the heat input through the tank domes is negligible. This way, a boundary layer model can be set up and by integrating the liquid mass flow in the natural convection boundary layer along a heated tank wall, an estimation for thermal stratification can be obtained. Additional assumptions are: the initial temperature of the liquid is uniform; the entire heat input into the tank wall appears at sensible heat in the boundary layer; the entire heat flux in this boundary layer goes into a heated upper stratum; the lower stratum remains at initial (bulk) temperature; and there is no mixing between the upper and lower strata. Following the procedure in [6], it is possible to compute a heated volume (volume of the upper stratum) and an average temperature in this heated volume. A schematic representation of the model is given in Fig. 4. Here, $T_{b}$ is the initial (bulk) temperature and $T_{s}$ is the liquid surface temperature. The average temperature of the heated volume will be somewhat between $T_{b}$ and $T_{s}$, depending on the temperature profile in the heated volume. 


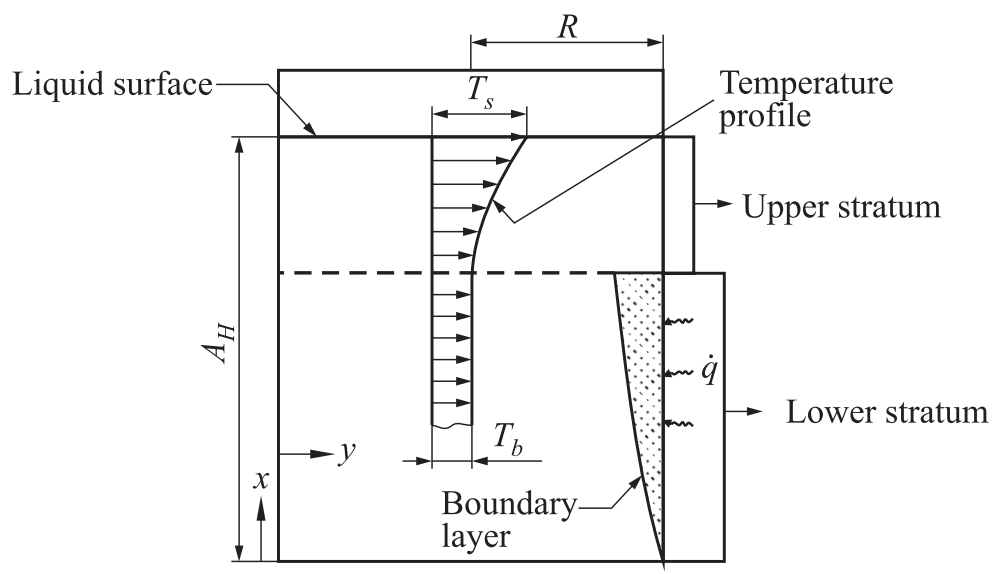

Figure 4 Stratification model [6]

The increase in the heated volume can be determined as

$$
\dot{V}_{H}=\left(A_{H}-\frac{V_{H}-\dot{V} t_{\mathrm{of}}}{A_{c}} 2 \pi R\right) \frac{h}{\rho_{l} c_{p_{\text {liq }}} \xi}
$$

where $\dot{V}_{H}$ is the volumetric increase of the upper stratum, $\mathrm{m}^{3} / \mathrm{s} ; A_{H}$ is the tank wall heated area, $\mathrm{m}^{2} ; V_{H}$ is the volume of the upper stratum, $\mathrm{m}^{3} ; \dot{V}$ is the volumetric outflow rate, $\mathrm{m}^{3} / \mathrm{s} ; A_{c}$ is the area of liquid surface, $\mathrm{m}^{2} ; t_{\mathrm{of}}$ is the time after start of liquid outflow, s; $R$ is the tank radius, $\mathrm{m} ; h$ is the wall-boundary layer heat transfer coefficient, $\mathrm{W} / \mathrm{m}^{2} / \mathrm{K} ; \rho_{l}$ is the liquid density, $\mathrm{kg} / \mathrm{m}^{3}$; and $\xi$ is the factor depending on temperature and velocity distributions in the boundary layer.

The average temperature in the heated upper stratum can be calculated using the following relation:

$$
\dot{T}_{\mathrm{av}}=\frac{1}{V_{H} \rho_{l} c_{p_{\text {liq }}}}\left(A_{H}-\frac{\dot{V} t_{\mathrm{of}} 2 \pi R}{A_{c}}\right) \dot{q}
$$

where $\dot{T}_{\mathrm{av}}$ is the growth rate of the average temperature in the upper stratum, $\circ / \mathrm{s} ; V_{H}$ is the volume of the upper stratum, $\mathrm{m}^{3}$; and $\dot{q}$ is the power of the heat flux, $\mathrm{W} / \mathrm{m}^{2}$.

By assuming a linear temperature profile in the upper stratum, the temperature at the liquid surface can be calculated from $T_{b}$ (bulk temperature) and $T_{\mathrm{av}}$ (the average temperature in the upper stratum). As soon as the temperature at the liquid surface reaches the saturation value, the evaporation process is called 


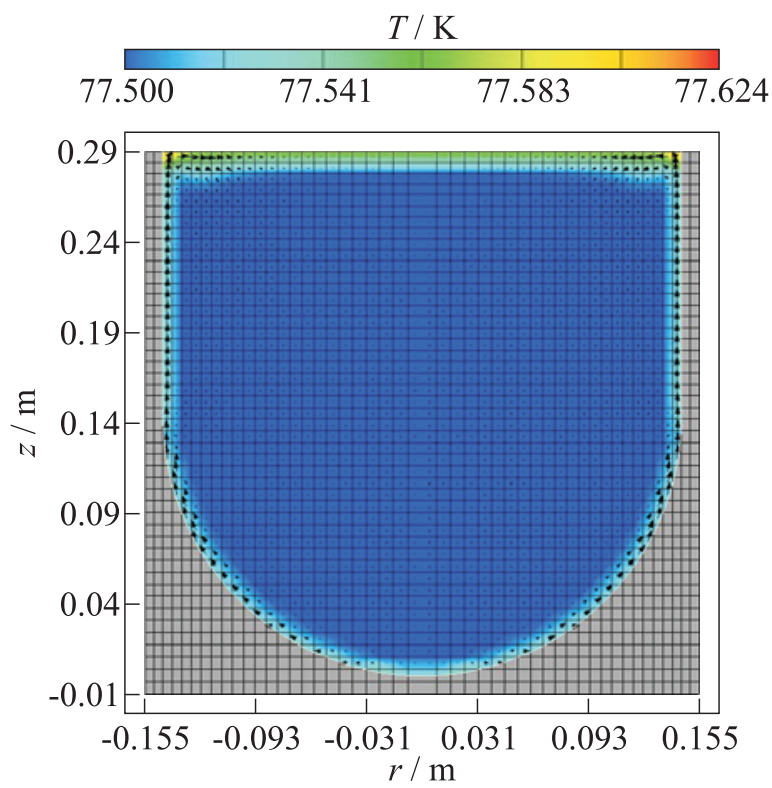

Figure 5 FLOW 3D model of stratification process of test at ZARM. (Refer van Foreest et al., p. 715.)

"natural convection boiling." Once the liquid surface temperature is known, the evaporation rate can be calculated using Eq. (1). The results of this simplified model will be compared with the results obtained from the FLOW 3D calculations. Figure 5 shows the results obtained by the FLOW 3D simulation of an experiment conducted at ZARM using liquid nitrogen $\left(\mathrm{LN}_{2}\right)$ as a fluid. The figure shows only a part of the test-tank filled with $\mathrm{LN}_{2}$. The heated boundary layer which transports the warm liquid into the upper stratum can be clearly seen, justifying some of the assumptions made in the model described above. In the future, simulations of real launch-vehicle tanks will be also made using FLOW 3D.

\section{FUTURE WORK}

The stratification model in its current form is limited to tanks heated through the cylindrical part only. This can be a good approximation when the tank is largely cylindrical and the dome surfaces are small compared to the cylindrical surface. This is the case in, for example, first-stage tanks. Additionally, a large part of the volume in the upper dome will be occupied by the ullage. In this case, the assumption that no heat will enter the liquid via the upper dome is valid. 
In applications where the dome surface is large compared to the cylindrical surface liquid heating through the domes cannot be neglected. This is often the case for upper-stage tanks. The WOTAN LOx tank illustrates this very well. The cylindrical part of this tank is almost zero and, thus, the liquid is heated only through the domes. This is clearly the example of a tank where the stratification model in its current state is not valid. A part of the future work will, therefore, be the adaptation of the model so that it can also be used for upper-stage tanks.

Another important part of the future work will be the implementation of the sloshing model. The sloshing model will not only determine the forces on the stages, but will also include a model for estimating the pressure drop encountered during cryogenic sloshing. The stratification and slosh model will be developed by investigating the results of 3D numerical analysis using FLOW 3D, as well as investigating the results of experiments executed at ZARM.

\section{CONCLUDING REMARKS}

Propellant Management Program is capable of simulating the propellant management system very fast. Some models have been adapted or added to increase its accuracy. For example, the phase change model has been improved and a stratification model has been added. Propellant Management Program shows good agreement with the Astrium EUCES tool for a simple adiabatic test case, although a slight difference in ullage temperature is present.

\section{REFERENCES}

1. Van Carey, P. 1992. Liquid-vapor phase change phenomena. Hemisphere publishing corp.

2. FLOW 3D user manuel. Version 9.3

3. Isselhorst, A. 2006. Simulation of launcher propulsion systems, study on numerical modeling and simulation of launcher stages for propelled and non-propelled flight phases. EUCAS Final Report. Part I. BMBF 50JR0503.

4. Isselhorst, A. 2008. Simulation of launcher propulsion systems, object-oriented programming of physical models for launcher propulsion systems. EUCAS Final Report. Part II. BMBF 50RL0620.

5. Sippel, M.; A. van Foreest, M. Jäger, and P. Philip. 2009. Study trade-offs on future European expendable launchers. 3rd European Conference for Aerospace Sciences (EUCASS). Versailles.

6. Ring, E. 1964. Rocket propellant and pressurization systems. Englewood Cliffs, N.J.: Prentice-Hall, Inc.

7. Chin, J. H., J. O. Donaldson, L. W. Gallagher, et al. 1964. Analytical and experimental study of liquid orientation and stratification in standard and seduced gravity fields. Lockheed Missiles and Space Comp. 